\title{
An Integrated Framework for Modeling Air Carrier Behavior, Policy, and Impacts in the U.S. Air Transportation System
}

\author{
Brant M. Horio ${ }^{1}$, Vivek Kumar ${ }^{2}$, Anthony H. DeCicco ${ }^{3}$, Shahab Hasan ${ }^{4}$, Virginia L. Stouffer ${ }^{5}$ \\ LMI, McLean, VA 22102 \\ and \\ Jeremy C. Smith ${ }^{6}$, Nelson M. Guerreiro ${ }^{7}$ \\ NASA Langley Research Center, Hampton, VA, 23681
}

\begin{abstract}
The implementation of the Next Generation Air Transportation System (NextGen) in the United States is an ongoing challenge for policymakers due to the complexity of the air transportation system (ATS) with its broad array of stakeholders and dynamic interdependencies between them. The successful implementation of NextGen has a hard dependency on the active participation of U.S. commercial airlines. To assist policymakers in identifying potential policy designs that facilitate the implementation of NextGen, the National Aeronautics and Space Administration (NASA) and LMI developed a research framework called the Air Transportation System Evolutionary Simulation (ATS-EVOS). This framework integrates large empirical data sets with multiple specialized models to simulate the evolution of the airline response to potential future policies and explore consequential impacts on ATS performance and market dynamics. In the ATS-EVOS configuration presented here, we leverage the Transportation Systems Analysis Model (TSAM), the Airline Evolutionary Simulation (AIRLINE-EVOS), the Airspace Concept Evaluation System (ACES), and the Aviation Environmental Design Tool (AEDT), all of which enable this research to comprehensively represent the complex facets of the ATS and its participants. We validated this baseline configuration of ATS-EVOS against Airline Origin and Destination Survey (DB1B) data and subject matter expert opinion, and we verified the ATS-EVOS framework and agent behavior logic through scenario-based experiments that explored potential implementations of a carbon tax, congestion pricing policy, and the dynamics for equipage of new technology by airlines. These experiments demonstrated ATS-EVOS's capabilities in responding to a wide range of potential NextGenrelated policies and utility for decision makers to gain insights for effective policy design.
\end{abstract}

\section{Introduction}

$\mathrm{T}$ HIS paper is an extension of research by Horio ${ }^{1}$ in which we first introduced the ATS-EVOS framework and its approach for exploring system-wide ATS performance impacts due to ATS stakeholder behaviors-in particular, behaviors of U.S. commercial airlines - under the influences of NextGen technologies and potential policies related to equipage and operational changes. The ATS is a highly interdependent and complex network of systems, subsystems, stakeholders, and policies. A change in any aspect of this system has cascading effects, ultimately influencing the safety, performance, environmental impact, and economics of the ATS as a whole. These

\footnotetext{
${ }^{1}$ Consultant, Operations and Cost Analysis, 2000 Corporate Ridge, AIAA Member.

${ }^{2}$ Consultant, Operations and Cost Analysis, 2000 Corporate Ridge, AIAA Member.

${ }^{3}$ Consultant, Operations and Cost Analysis, 2000 Corporate Ridge.

${ }^{4}$ Program Director, Operations and Cost Analysis, 2000 Corporate Ridge, AIAA Senior Member.

${ }^{5}$ Program Manager, Operations and Cost Analysis, 2000 Corporate Ridge, AIAA Senior Member.

${ }^{6}$ Research Aerospace Engineer, Aeronautics Systems Analysis Branch, Mail Stop 442, AIAA Member.

${ }^{7}$ Research Aerospace Engineer, Aeronautics Systems Analysis Branch, Mail Stop 442, AIAA Member.
} 
stakeholder-level decisions and behaviors have both a tactical and a strategic perspective, and they are influenced by socioeconomic, technological, and policy interactions.

U.S. commercial airlines are a key stakeholder in the ATS and successful implementation of NextGen requires airlines to equip their fleets with enabling technologies, with the bulk (if not all) of the capital expense at their own cost. There are potentially significant installation costs involved and policies are necessary to best incentivize airlines to equip their fleets. The ATS-EVOS framework is from a stakeholder perspective and as such, leverages models developed in an agent-based context to more easily represent individual and organizational behaviors in response to proposed policies and other changes in the system².

Ultimately, we seek to provide a tool for decision makers to gain better insight into how the design of policies and incentives may help ensure system performance is balanced with stakeholder utilities, and reduces risk and uncertainty for achieving a more efficient, robust, and safer ATS. The focus on this paper is not on a specific model, but is in reference to the overall ATS-EVOS framework, the integration of its component models, and the utility of the approach.

\section{Research Approach}

We developed a research framework to sufficiently represent the real-world ATS in Horio ${ }^{1}$, focusing on the dynamic interactions between airlines, customers, and policy. This approach-which is modular and uses different computational tools to address the modeling components for demand generation, airline behavior, ATS performance, and environmental assessments - is called ATS-EVOS.

We have since refined and expanded the framework and in the particular configuration of ATS-EVOS that we discuss in this paper, we leverage TSAM ${ }^{3}$, AIRLINE-EVOS ${ }^{1,4}$, ACES $^{5}$, and AEDT. A high-level diagram of the ATS-EVOS framework and the interaction between its modeling components and input data sets is shown in Fig. 1.

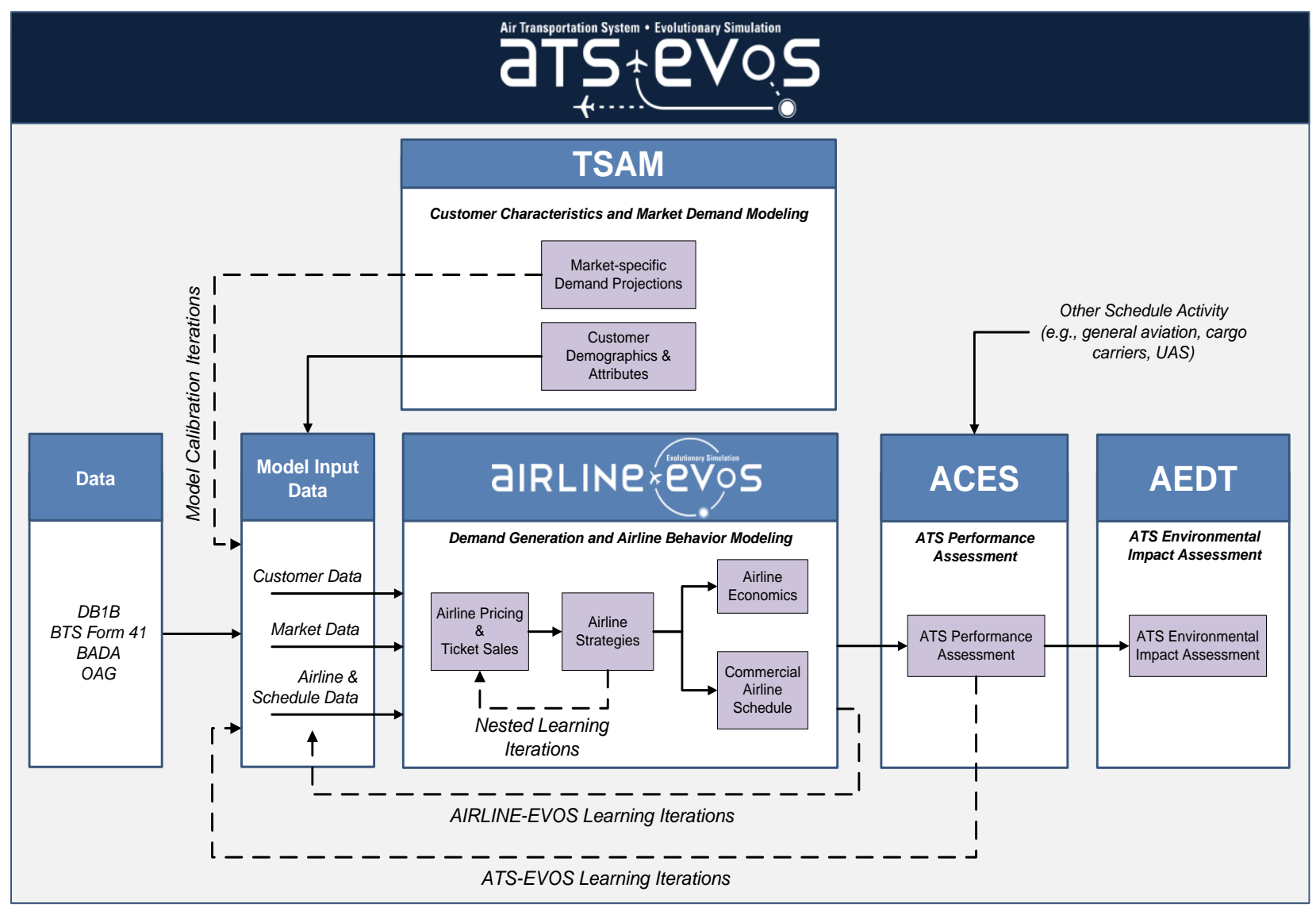

Figure 1. ATS-EVOS Framework. This figure shows a high-level overview of the ATS-EVOS framework and how external data inputs and the individual computational modeling components relate to each other. The dashed line connections highlight iterative feedback loops that are used for model calibration and agent learning.

American Institute of Aeronautics and Astronautics 


\section{A. Modeling Components of ATS-EVOS}

ATS-EVOS employs in its current configuration uses four component models:

- Virginia Tech's TSAM is a transportation mode choice model with a national scope and is used by ATSEVOS for (1) calibrating AIRLINE-EVOS simulated market demand to the projected commercial air travel demand from TSAM scenario runs, and (2) for assigning representative demographic characteristics to every customer agent within AIRLINE-EVOS. These characteristics are specific to each agent and include travel type (business, leisure), household income, ticket purchasing behavior preferences, and individual perception of other decision factors such as value of time.

- LMI's AIRLINE-EVOS simulates airline agents and their behavioral responses due to interaction with the customer agents, other airlines, and systemic conditions of the ATS. AIRLINE-EVOS employs an agentbased approach to simulating these agent behaviors and interactions, ideal for the complex system dynamics in the ATS; airline agents are adaptive, making tactical and strategic changes to their airfares, network, and schedules under the influence of reinforcement learning, to best generate profit and compete in markets. Customer agents choose to purchase or not purchase airline tickets. Our research with this model has simulated as many as 26 individual airlines in three business model categories (full-service, lowcost, and regional) and their interactions with nearly one million customer agents over 30,800 daily flights.

- NASA's ACES model simulates system-wide effects of proposed air transportation concepts and is used by ATS-EVOS to track the related performance impacts of AIRLINE-EVOS simulated decisions by the airline agents. AIRLINE-EVOS outputs a modified flight schedule as a result of airline decisions; we need a tool to assess the consequential impacts of those decisions in the ATS. These impacts measures are related to flight delay and congestion in the airspace.

- FAA's AEDT also models performance at an aircraft level and is used by ATS-EVOS to track fuel burn, emissions, and noise. This is a new feature of the ATS-EVOS suite and allows environmental impacts to be included with our experiment results.

In addition to these component model parts, AIRLINE-EVOS accepts data input from external sources to give our airline and customer agents more robust characteristics. The data include operational costs from the Bureau of Transportation Statistics (BTS) Form 41, aircraft performance characteristics from the EUROCONTROL Base of Aircraft Data (BADA), and starting airfare pricing parameters from the BTS Airline Origin and Destination Survey (DB1B). In addition, we use DB1B and the Official Airline Guide (OAG) as a source for validation patterns to compare against AIRLINE-EVOS outcomes.

\section{B. ATS-EVOS Process Flow}

The general process flow for the ATS-EVOS framework shown in Fig. 1 is described in the following steps. Except for Step 1, all are major updates since Horio ${ }^{1}$.

1) Data from TSAM and other sources are loaded into AIRLINE-EVOS, and agent populations are instantiated for airlines, customers, and markets. Necessary calculations are made for assigning individual agent characteristics and other behavior-driving factors.

2) Once the AIRLINE-EVOS system has been set up, a calibration loop-indicated by a dashed line - is started to match AIRLINE-EVOS simulated outcomes for airfare and demand to TSAM projections, as described in Kumar ${ }^{6}$. This calibration process implemented a search algorithm that iteratively adjusted on a market level, airfares and customer willingness-to-pay. This is a significant development since our previous publication in that it enables existing TSAM functionality to be included in our analysis assumptions, such as the influences of new modes of travel (e.g., high-speed rail, on-demand mobility) that compete with demand for commercial air travel. It also enables the use of TSAM-based scenarios that use projections for future fleet evolution and schedule changes.

3) Given a calibrated AIRLINE-EVOS model, we simulate airline and customer interactions within AIRLINE-EVOS. We may optionally use multiple iterations of this model run to allow airlines to learn from repeated customer interactions. At the end of the iteration cycles, AIRLINE-EVOS generates an output flight schedule that has been modified in line with airline agent decisions under influences of reinforcement learning.

4) The AIRLINE-EVOS output flight schedule is processed in ACES to measure the performance impacts on the ATS. 
5) Steps 3 and 4 are repeated for some number of replications to allow airline agents to evolve over some period of time and through reinforcement learning based on feedback loops from ACES results. Effects, in the form of delay metrics, are input back into AIRLINE-EVOS where they are monetized and incorporated into subsequent airline decisions, allowing them to more robustly evolve their response while accounting for observed performance in the airspace, changing market dynamics due to consumer decisions, and competitive effects between airlines. This is important for fully exploring system dynamics for scenarios such as equipage of new technologies. Based on operational feedback results of prior investment decisions, these realized benefits may update subsequent cost/benefit calculations and spur expanded fleet equipage.

6) Steps 1 through 5 are fully automated through an automation script that processes data, runs the model components in a serial fashion, and between modeling steps, modify output data as necessary into a format compatible for input into the next model. At this time, AEDT is not part of the automated process and has been used only when the specified number of ATS-EVOS replications have been run. When appropriate, we export the final ACES run output data into AEDT. We use this model to measure environmental impacts, specifically, the emissions effects on the system due to the AIRLINE-EVOS schedule adjustments. This may be viewed as determining the environmental impacts of the convergent state of an ATS-EVOS scenario for making relative comparisons against the experiment baseline.

AIRLINE-EVOS also experienced major improvements to its model structure and functionality but its specific updates are further discussed in Horio $^{3}$, currently in consideration for publication. These updates are primarily focused on implementation of a more robust and representative set of behavioral responses for the airline agents with respect to network modification and schedule adjustment logic. We present in the appendix, an updated model description of AIRLINE-EVOS from Horio ${ }^{1}$ using a standard protocol known as ODD (Overview, Design concepts, and Details $)^{7,8}$. The ODD here is abbreviated. For the full ODD description, reference the final NASA report ${ }^{10}$.

\section{Verification and Validation}

We conducted verification and validation $(\mathrm{V} \& \mathrm{~V})$ through comparisons of a baseline scenario of ATS-EVOS against validation patterns representative the current time frame to help establish the legitimacy of the virtual world within which ATS-EVOS and AIRLINE-EVOS operate.

\section{A. Verification}

Our baseline scenario of ATS-EVOS followed the process discussed in the previous section. Using our calibrated airfares and customer WTP values, we allow the ATS-EVOS iterations to evolve from that starting point and establish the baseline case. We simulated three iterations of the entire ATS-EVOS cycle with ACES in the loop and using a 2012 baseline flight schedule. Results are shown in Fig. 2 and describe how system enplanements and mean airfare have changed over the different ATS-EVOS iterations.
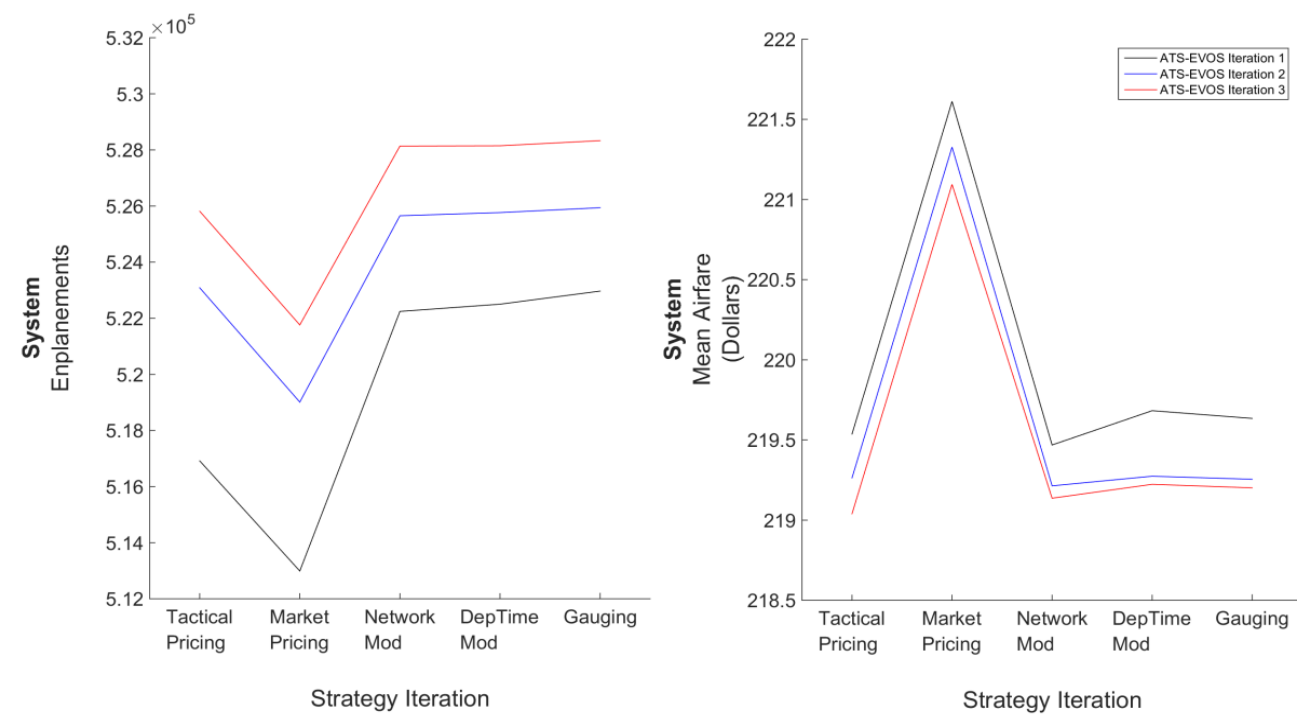

Figure 2. ATS-EVOS baseline for enplanements and mean airfare. This figure shows simulated airfares in comparison to DBIB results. Dashed lines indicate the distribution means.

American Institute of Aeronautics and Astronautics 
Airline agents in AIRLINE-EVOS sequentially execute five strategic behaviors to adapt to changing conditions in the market and due to competition. These strategies have the objective - as in the real world - to improve airline profits and performance. The primary mechanism for this is related to adjusting airfares and/or the schedule offerings to make their airline service more attractive to the public. With respect to airfares, pricing is decreased to regain lost demand and gradually increased during sustained periods of ticket sales in order to capture as much profit as possible. For scheduling-related strategies, airlines may adjust departure times, service frequency, and their network structure to better meet demand needs. The results in Fig. 2 indicate that airline strategies are functioning as intended, which is for the airlines to ultimately fill seats and make revenue-as enplanements go down, airfares are dropped to attract more sales, and as enplanements go up, airfares are carefully and incrementally increased. We observed that of all the strategies, market pricing adjustments are the most aggressive in raising mean airfare, and in general, as airfares become more affordable, enplanements increase. Airfare changes in baseline conditions move in a very incremental manner, and as the model evolves over multiple ATS-EVOS iterations, variances between successive iterations decrease, suggesting a trend toward convergence. It should be noted that our baseline input schedule and data do not account for seasonality changes and other major perturbation factors and assumes a fairly constant system. Off-nominal conditions such as seasonal peak effects may be explored in ATS-EVOS and just requires a more specific experiment scenario.

As further V\&V for airlines strategies, we observe in Fig. 2 that by the third iteration, airfares, after airlines employ strategic behaviors, are higher than the airfares at the beginning of the ATS-EVOS iteration. Paired with the insights that enplanements also increase, results suggest that the airline strategies are helping airlines evolve their operation into more lucrative scenarios. This is further corroborated with our tracking of industry-wide metrics in the model that show airline profits increasing over time.

\section{B. Validation}

Validation was conducted by comparing AIRLINE-EVOS outputs against Airline Origin and Destination Survey (DB1B) data, a 10-percent quarterly sample of all airline tickets sold in the U.S. and is the most accessible and relevant data for U.S. commercial airline airfares. The distribution of DB1B trends also provide a validation pattern for the entire ticket purchasing process, including how airlines price airfares and how customers, in turn, decide which tickets to buy, if at all. The validation of this overall process effectively validates AIRLINE-EVOS in its entirety, with respect to sufficiently capturing the complexity of the internal system mechanics to ultimately result in the overall system performance. Simulated results from AIRLINE-EVOS and its comparison to relevant DB1B results are shown in Fig. 3. Both results are representative of the $3^{\text {rd }}$ quarter in 2012; AIRLINE-EVOS uses a 2012 historical flight schedule calibrated to 2012 TSAM model results, and DB1B data is representative of the same timeframe as the flight schedule.

We do not expect the comparison of results in Fig. 3 to match exactly because we are modeling simplified airline behaviors that may not capture variability factors inherent in the DB1B data, such as seasonality, airline yield management practices, and day-ofweek pricing strategies. We are also only simulating a single representative day. We use this validation pattern to gain insights into how our abstraction of airfare pricing logic - which considers advance purchase day, load factor at time of purchase, marketspecific base airfare, customer willingness-to-pay estimates, and options for nonstop or a single connection itinerary-sufficiently captures the complexity of realworld pricing. Given these considerations, comparison of mean airfares in Fig. 3 suggest that AIRLINE-EVOS airfare pricing logic is fairly representative of the real world. Customer decisions about tickets to purchase are

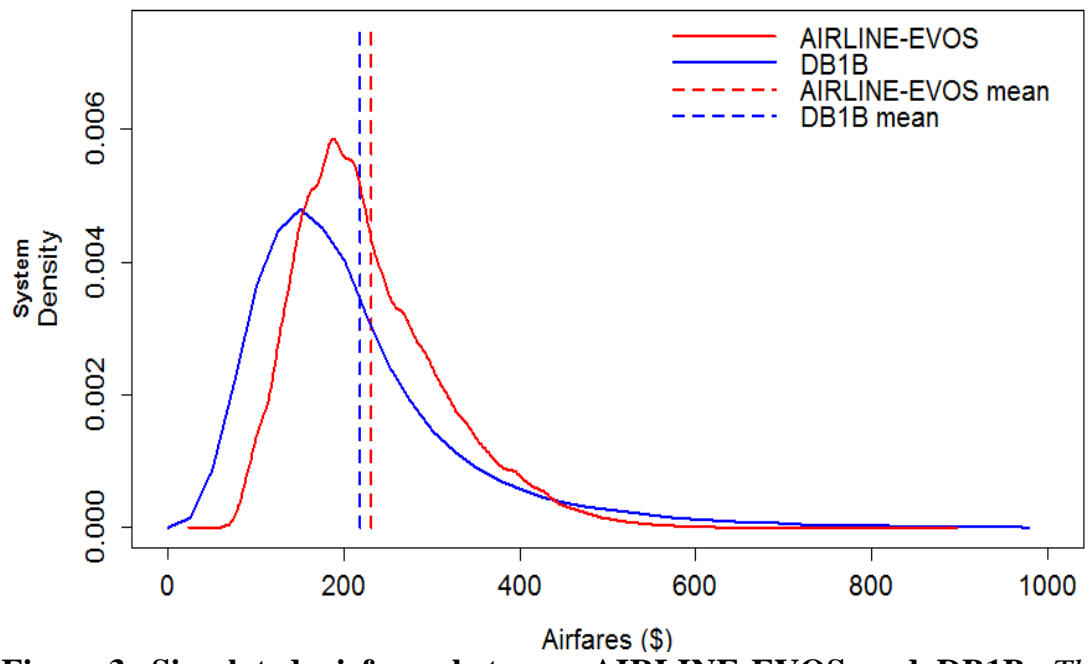

Figure 3. Simulated airfares between AIRLINE-EVOS and DB1B. This figure shows simulated airfares in comparison to DB1B results. Dashed lines indicate the distribution means. 
dependent on the airfares offered, thus validation of consumer choice-as observed by the comparison of distribution shape between AIRLINE-EVOS and DB1B - simultaneously offers approximate visual validation for the ticket purchasing logic of our customer agents.

\section{Proof-of-Concept Experiments}

We further verified the ATS-EVOS framework and agent behavior logic through three scenario-based experiments. These experiments demonstrate ATS-EVOS's capabilities in responding to a wide range of potential NextGen-related policies and provides us confidence that our research approach and modeling framework, when used in rigorous analytical studies, would yield decision-quality results. These results however are not designed for, nor intended to directly inform policy decisions. Future analyses would follow a similar experimentation process but would require more complex and detailed experiment parameters.

\section{A. Experiments}

Airline behaviors influence the performance of the ATS and the service provided to consumers. Airline decisions related to pricing, scheduling, and resource allocation are key to these impacts, influencing congestion, delay, and customer quality of service. We sought in these proof-of-concept experiments a way to ensure that our approach provides system performance metrics that account for representative airline responses to proposed policies.

This modeling of airline behaviors in the context of the ATS-EVOS framework, forms the foundation for exploring three airline response dynamics we were interested in. These scenarios were focused on (1) adaptive response to operating cost changes, (2) mitigation of overscheduling behaviors, and (3) evolutionary response to investment decisions. The experiments with some further details are shown in Table 1.

Table 1. Proof-of-concept experiments.

\begin{tabular}{|ll|}
\hline \multicolumn{1}{|c|}{ Experiment } & \multicolumn{1}{c|}{ Description } \\
\hline $\begin{array}{l}\text { Adaptive Response to } \\
\text { Operating Cost Changes }\end{array}$ & $\begin{array}{l}\text { Focused on a notional carbon tax, scoped as a national policy affecting all } \\
\text { airlines. Assesses impacts and airline response to operating cost increases. }\end{array}$ \\
\hline $\begin{array}{l}\text { Mitigation of Overscheduling } \\
\text { Behaviors }\end{array}$ & $\begin{array}{l}\text { Focused on a notional congestion pricing policy, scoped to be locally } \\
\text { implemented at a single, highly congested airport. Assesses congestion pricing } \\
\text { impacts on airline scheduling behaviors. }\end{array}$ \\
\hline $\begin{array}{l}\text { Evolutionary Response to } \\
\text { Investment Decisions }\end{array}$ & $\begin{array}{l}\text { Explore decision logic and influencing factors for our model's abstraction of } \\
\text { an airline's assessment of costs and benefits for a new technology, the } \\
\text { decision to incrementally equip their fleet, and the potential evolution of that } \\
\text { decision over time. }\end{array}$ \\
\hline
\end{tabular}

We discuss the experiments for adaptive response to operating cost changes using a notional carbon tax scenario, and also for evolutionary response to investment decisions in Horio $^{3}$. In that discussion, we found that in the carbon tax scenario, we observed airline agents sense revenue implications and adapt their pricing and scheduling responses to maintain profitability. In the results for exploring the evolutionary response to investment decisions, we illustrated how airline agents make profit-maximizing decisions that can be informed by system performance feedback from prior states, and through learning, allow airlines to evolve their decision making over time to better match environmental conditions.

We focus our discussion in this paper on the proof-of-concept experiment exploring potential policy for mitigation of overscheduling behaviors. We believe it is particularly relevant for this paper as it depends upon the feedback loop from the ACES component for informing subsequent AIRLINE-EVOS decisions. It is our opinion that demonstrating representative mechanics for this behavioral response-in conjunction with other findings presented in $\mathrm{Horio}^{3}$ - shows that emergent outcomes from ATS-EVOS experiments are plausible and reasonable, and provides strong evidence that this approach may be used for research into many topics of interest for NASA and the larger aviation research community.

\section{B. Proof-of-Concept Scenario for Congestion Pricing Policy}

This experiment explored a potential disincentive designed to improve service levels at congested airports. We investigate the effectiveness of such policies in decreasing congestion and delays. An optimal policy would have 
minimal impact on enplanements, by essentially relating the airline cost structure at congested airports to the airlines' scheduled flight times and force a more efficient flight schedule.

At some airports, runway service demand is so high during peak traffic periods that the airport is overwhelmed and runway queues form, resulting in long delays. For some of these airports, the problem is restricted to a few, relatively brief periods; the airports' runway resources are underused at other times of the day. Where this is this case, mitigating the service issues may be possible by implementing policies that

- discourage flight scheduling during high-traffic periods,

- encourage flight scheduling during low-traffic periods, or

- a combination of the two.

Congestion pricing is a method for imposing a congestion-based fee on the use of a limited public resource so as to reduce congestion. This experiment explores the use of a congestion pricing policy and its associated impacts on airline scheduling behaviors, which includes overscheduling. The overscheduling behavior at specific times of the day coincide with disproportionate demand for tickets during these travel times. These peak demand travel times are therefore very profitable to the airlines because they are able to charge premiums in the form of higher ticket prices. The higher profitability of these slots exacerbates the overscheduling behavior of airlines because they all want to maximize their operating profits.

Historically, some airports have dealt with flight congestion through fixed landing fees. Using a fixed fee per aircraft, rather than a weight-based fee, encourages airlines to use fewer and larger aircraft during peak use periods, since the cost of the fee per customer is lower and revenue per fee higher.

Finally, some New York metroplex airports have levied fees upon aircraft that use the airports during congested periods. In this case, only certain aircraft are affected, and the fee was levied only on aircraft having fewer than some number of seats determined by the airport. The effect of this policy was to discourage GA flights out of the busiest New York airports. This is the only implementation that directly penalizes operations during the peak-use period.

\section{Method}

AIRLINE-EVOS is capable of modeling any of the aforementioned congestion pricing implementations, but the most informative experiment is to model the strongest form of congestion pricing possible, which would be to model an expansion of the third type of implementation, where any aircraft using the airport during congested periods would have to pay a fee. To encourage the use of larger aircraft, the fee should be flat.

Johnson ${ }^{9}$ conducted a study focused on Chicago O'Hare (ORD), which is a highly congested airport, especially in the latter part of the day. The study estimated the relationship between the number of flights wishing to depart and the delays they experience, to calculate congestion fees designed to incentivize airlines to move some flights from the peak period and/or adjust departure times.

Table 2 shows the congestion fee results ${ }^{9}$ for four different airlines, identified in the table by their ORD market share at the time of the study. The fees are based on six different late-day hour-long epochs, starting from 15:00 and ending at 20:00. Because of the marginal disutility imposed on the system and to the airlines themselves, you can see that the fee amounts are lower for airlines with greater market shares, based on an assumption that more dominant airlines have an inherent incentive to keep congestion low and do not require as much of a financial penalty to drive behavior.

Table 2. Congestion pricing fees at ORD, by market share and peak period hour epochs.

\begin{tabular}{|c|c|c|c|c|c|c|}
\hline \multirow{2}{*}{ Market share } & \multicolumn{7}{|c|}{ Peak period hour epochs } \\
\cline { 2 - 7 } & $\mathbf{1 5 : 0 0}$ & $\mathbf{1 6 : 0 0}$ & $\mathbf{1 7 : 0 0}$ & $\mathbf{1 8 : 0 0}$ & $\mathbf{1 9 : 0 0}$ & $\mathbf{2 0 : 0 0}$ \\
\hline Atomistic & $\$ 16,878$ & $\$ 12,848$ & $\$ 9,958$ & $\$ 8,688$ & $\$ 5,241$ & $\$ 670$ \\
\hline 0.023 & $\$ 16,482$ & $\$ 12,546$ & $\$ 9,724$ & $\$ 8,484$ & $\$ 5,118$ & $\$ 655$ \\
\hline 0.405 & $\$ 10,035$ & $\$ 7,638$ & $\$ 5,920$ & $\$ 5,165$ & $\$ 3,116$ & $\$ 399$ \\
\hline 0.488 & $\$ 8,629$ & $\$ 6,569$ & $\$ 5,091$ & $\$ 4,442$ & $\$ 2,680$ & $\$ 343$ \\
\hline
\end{tabular}


The study was conducted in 2006, so assuming that the congestion pricing relationships between market share and fee are still valid in our current 2012 schedule scenarios, we adapt these study results to fit our experiments. We do so by using the values in Table 2 to generate simple linear regression models for each epoch. We show the resulting pricing fee models in Fig. 4.

The two main trends observed in the pricing models shown in Fig. 4 are that it is cheaper to fly later in the congestion pricing time window, and within a given time epoch, the congestion pricing fee decreases as market share increases.

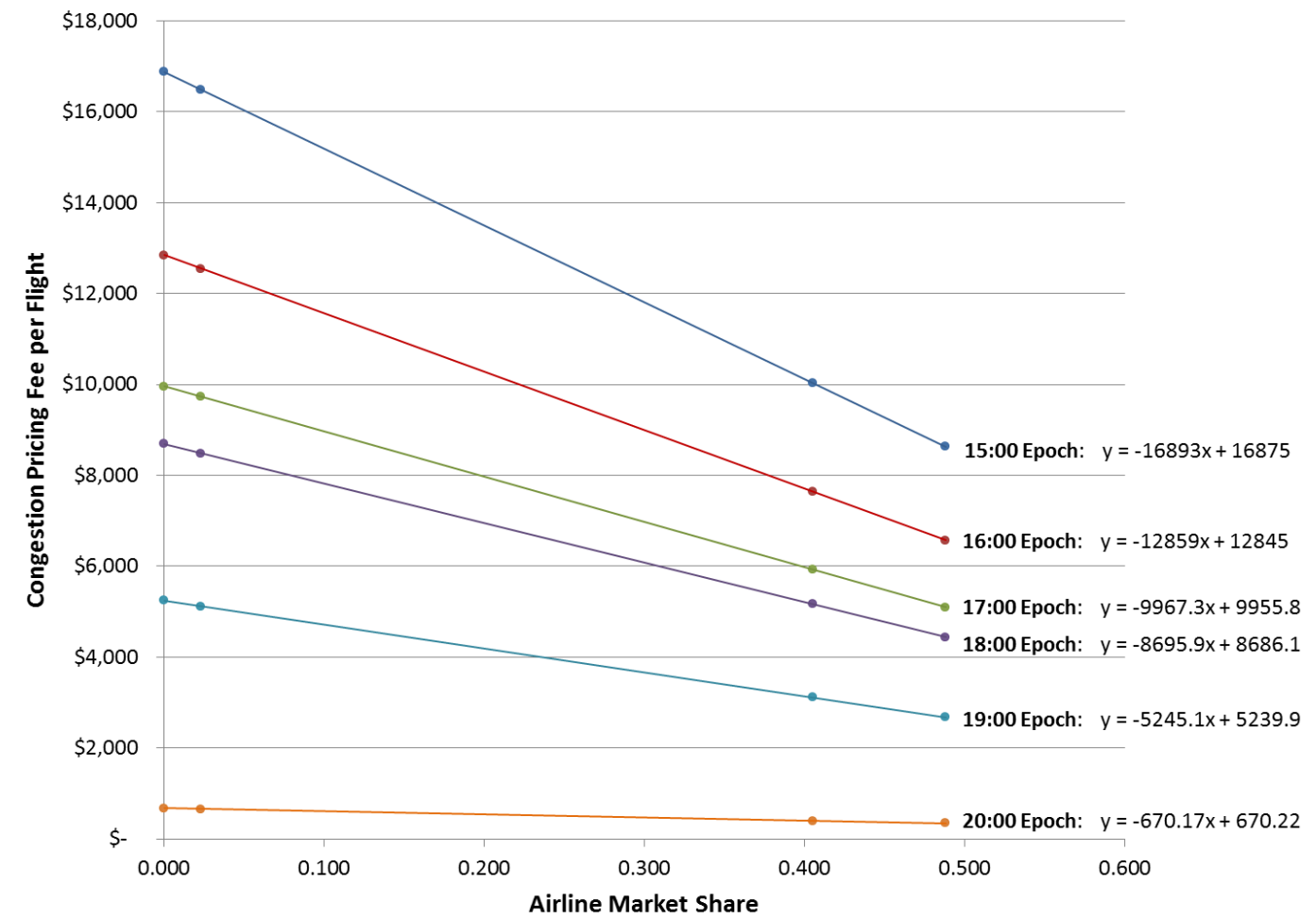

Figure 4. Drop in congestion pricing fee models for ORD by market share. This chart shows our ORD congestion pricing fee models that were adapted from research by Johnson ${ }^{9}$.

We implement these models into AIRLINE-EVOS, applying them only to ORD departures that leave within the specified epochs. The congestion pricing fees are added to flight costs within the model; if they sufficiently penalize a flight's profits, they will be subject to strategic action (e.g., network or departure time modification, gauge change). Airline market share is allowed to be dynamic to reflect change as the model evolves and consumers respond to airline decisions. Each new iteration of ATS-EVOS will determine an updated ORD market share that will be used in the AIRLINE-EVOS modeling component for applying the congestion pricing fee.

The overall research approach for conducting experiments within the ATS-EVOS framework follows a process of establishing a baseline following the process outline of Fig. 1, including seeding the initial AIRLINE-EVOS run with inputs from a baseline ACES run and TSAM calibration. We then run through the same process againrepeatedly for a specified number of iterations - providing outputs from individual models as inputs to subsequent modeling steps of ATS-EVOS after introducing rules and values for projected impacts for a given experiment scenario. This enables a comparison of emergent model run results against the baseline to determine relative differences with respect to ATS performance impacts and environmental metrics. Experiments were run for a historical flight schedule in 2012. This particular experiment did not include an assessment of emissions impacts using AEDT, though the capability to do so existed.

\section{Results}

We first assess the ACES-simulated schedule impacts due to our implementation of the congestion pricing policy. As explained earlier, this study was limited in scope by only applying the congestion pricing fee to departures from ORD, a total of 1,083 flights. Table 3 shows, for the 2012 baseline and congestion pricing 
scenarios, the count of delayed flights and average delay durations related to ORD takeoff delays. One of the main objectives of implementing a congestion pricing policy is to reduce excessive congestion during peak periods. The results in Table 3 confirm that this objective is met because the number of flights delayed at takeoff drops from 787 flights to 783 flights. The average takeoff delay of the departures at ORD also reduces by 0.01 minute. Despite observing a reduction in takeoff delays in the congestion pricing scenario, the magnitude of these reductions is minimal. This may be because the congestion pricing fees do not negatively impact flight profitability enough to cause the airlines to move their departures to a less costly departure time.

Table 3. ORD departure schedule performance for congestion pricing experiment using 2012 flight schedule.

\begin{tabular}{|l|c|c|c|}
\hline \multicolumn{1}{|c|}{ ATS metric } & $\begin{array}{c}\text { Baseline } \\
\text { performance } \\
\text { (Iteration 3) }\end{array}$ & $\begin{array}{c}\text { Scenario } \\
\text { performance } \\
\text { (Iteration 3) }\end{array}$ & $\begin{array}{c}\text { Change from } \\
\text { baseline }\end{array}$ \\
\hline Total number of flights delayed for takeoff & 787 flights & 783 flights & -4 \\
\hline Flights with over 15 minutes of takeoff delay & 0.0 flights & 0.0 flights & 0 \\
\hline Average takeoff delay per flight (all flights) & 1.22 minutes & 1.21 minutes & -0.01 \\
\hline Average takeoff delay per flight (delayed flights only) & 1.68 minutes & 1.67 minutes & -0.01 \\
\hline
\end{tabular}

One of the main purposes of this experiment was to explore the effectiveness of a congestion pricing-based policy on overscheduling practices. Fig. 5 shows the change in the ORD departure schedule during the congestion pricing policy time frame. The blue line shows the original departure counts for each time epoch - where each epoch represents 1 hour - and the orange line shows the departure counts for the congestion pricing experiment. The $\mathrm{x}$-axis starts at 14:00 because the congestion pricing is applied only to the flights departing after 15:00. Since the congestion prices decrease from 15:00 to 21:00, we expect that some flights in the high peaks of the original schedule will shift to later (and hence cheaper) departure times, which is exactly what we observe. For example, at 16:00, there is a drop in the departure count and a shift from that peak into the next time epoch. A similar event of peak reduction is observed at 18:00 with a rescheduling to a later time at 19:00.

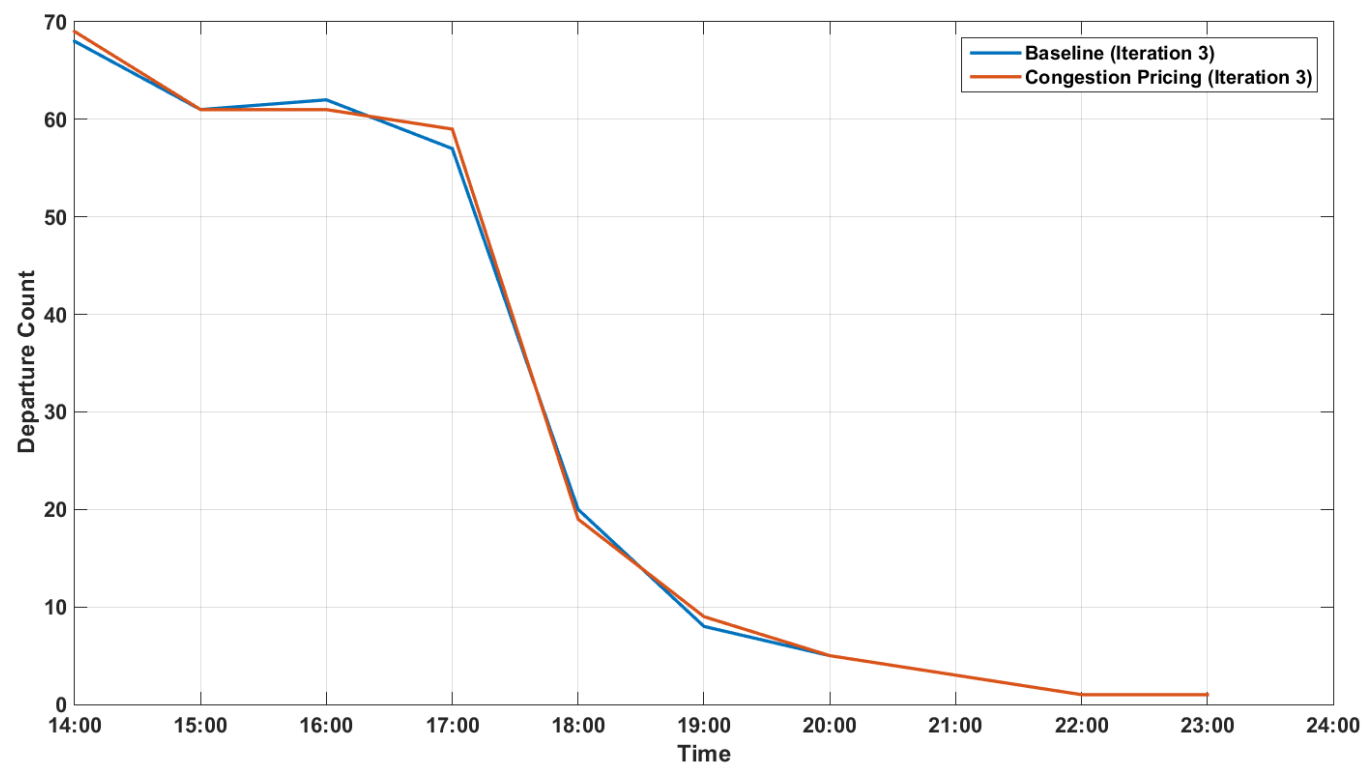

Figure 5. Change in departure schedule at ORD due to congestion pricing policy scenario. This plot shows schedule depeaking that resulted from airlines considering our notional congestion pricing scenario over multiple iterations of the ATS-EVOS simulation cycle. 


\section{Conclusion}

In our research progress from Horio ${ }^{1}$, we have demonstrated in our ATS-EVOS framework and its component simulation models, the viability and utility of this approach for enabling a method to:

- Quantify the effects of modeled airline behavior with inputs representing the current ATS and a projected future state of the ATS.

- Quantify the effects of incentive policies to explore airline responses such as the prevention of overscheduling and reduction of carbon emissions.

- Quantify the effects of competition from other modes of transportation, including high-speed rail and private air vehicles.

- Quantify the effects of new technologies on airline equipage behavior.

We used our fully operational ATS-EVOS framework to conduct three experiments that improved upon the initial analyses. Those experiments assessed notional and simplified policies for a carbon tax, congestion pricing, and introduction of new technology for equipage. The experiments leveraged an AIRLINE-EVOS model that is calibrated to TSAM, may be run over multiple iterations of ATS-EVOS, and accounts for schedule delays (and any relevant equipage benefits) as simulated by ACES in a previous iteration. Multiple iterations of ATS-EVOS allow the system to learn and evolve over time, a critical dynamic for robustly assessing future policies and their impacts on the ATS. Each experiment, except for the equipage scenario, was conducted using a 2012 schedule to represent the current system and in a similar process, is capable of representing a projected future state of the system by using a different input flight schedule.

Our experiments were successful in that we demonstrated the ATS-EVOS approach as a viable tool that can produce meaningful metrics for analyzing airline behaviors. Our observed results, while slight in movement, exhibit directional trends that seem to be reasonable, explainable, and representative of the real-world system. We also validated the results with our team of industry experts. The results from our experiments are not designed or intended to directly inform policy decisions; future analyses would use the experimentation process outlined in this report but would require more complex and detailed experiment parameters.

For a full reference of the final research, please see the final NASA report ${ }^{10}$.

\section{Appendix: AIRLINE-EVOS Model Description}

We now describe AIRLINE-EVOS, along with its general formulation, using a standard protocol known as ODD (Overview, Design concepts, and Details) ${ }^{7,8}$.ODD was designed to create factually complete and easily understood model descriptions that are standardized and consistent ${ }^{8}$. What we present here is an abbreviated ODD; readers should reference our full report to NASA for the complete ODD description. ${ }^{6}$

\section{A. Overview}

1. Model Purpose

The purpose of AIRLINE-EVOS is to formally model airline behaviors, accounting for their response to customer ticket purchasing choices and other external environmental factors-such as NextGen and FAA policy implementations - to enable the analysis of consequential, systemic impacts on the ATS as a whole and with respect to the system stakeholders.

\section{Customer Agents and State Variables}

The model has two different entities: customers and airlines. They are modeled as distinct agents that behave autonomously and interact with each other, accounting for influences and constraints introduced by specified external factors. We first discuss customer agents.

Customer agents are modeled as heterogeneous agent populations, with a number of differentiating attributes, including the origin-destination (O-D) pair that defines the agent's desired route. In the current version of AIRLINEEVOS, their behavior is strictly concerned with making a decision about whether to purchase an airline ticket, and which ticket to purchase. Modeling that behavior requires (1) a customer population based on forecasted demand, (2) relevant state variables, and (3) agent behavior logic for identifying feasible candidate ticket options and selecting a ticket from among those candidates based on preferences specific to the agent. After selecting airline tickets, the role of the customer agents in the model has been satisfied

AIRLINE-EVOS instantiates multiple customer populations at the beginning of each model run, each unique in size and specific to an air travel market defined by an O-D pair. The model uses market demand curves generated 
from previous research on market elasticities ${ }^{11}$ - specific to O-D pairs and to the type of travel, business or leisurewhich determines the number of potential customers that may buy tickets, as well as the amount each customer is willing to pay for a single ticket. Thus the customer willingness to pay (WTP) attribute is integrally linked with the size of a market's demand. We then calibrate for each market, its WTP curve through a search algorithm described in $\mathrm{Kumar}^{6}$. In this way, we get close to accurately matching the level of market demand projected by TSAM scenarios through approximating customer decisions to not purchase a ticket if all of the offered airfares are more expensive than the maximum amount they are willing to pay.

We also use TSAM results to assign customer agent-specific attributes, derived from how TSAM segments its output. In particular, we are interested in demographics of customers in each air travel market, including leisure or business traveler status, and the distribution of household income among those two categories, all of which is provided in TSAM output. The customer agent state variables used in AIRLINE-EVOS are described in Table A1.

Table A1. Customer agent state variables.

\begin{tabular}{|c|c|}
\hline State Variable & Description \\
\hline Desired O-D travel & $\begin{array}{l}\text { Customers are instantiated in groups, as segmented by TSAM, each with a specific } \\
\text { O-D pair. For each agent, we assign an appropriate origin airport and destination } \\
\text { airport matching the O-D pair of the group they were instantiated from. }\end{array}$ \\
\hline Traveler type & $\begin{array}{l}\text { Decisions made by customers are motivated by the type of traveler they are, } \\
\text { categorized in AIRLINE-EVOS as either business or leisure. TSAM segments } \\
\text { each O-D demand forecast by the same traveler type categories, enabling us to } \\
\text { assign each agent with a traveler type according to the ratio determined by TSAM, } \\
\text { during the AIRLINE-EVOS instantiation. This state variable will be a factor in } \\
\text { determining a customer's advance purchase time, arrival time sensitivity, and } \\
\text { airfare price sensitivity. }\end{array}$ \\
\hline Household income & $\begin{array}{l}\text { TSAM further segments each O-D demand forecast into five income range } \\
\text { brackets. We use this segmentation of the demand to derive a specific income from } \\
\text { the ranges for each customer agent. }\end{array}$ \\
\hline Value of time & $\begin{array}{l}\text { We quantify an approximation for perception of the value of time of each customer } \\
\text { agent, to be used in the decision-making process for a customer to select an airline } \\
\text { ticket to purchase. It acts as a weighting coefficient that makes more inconvenient } \\
\text { itinerary options less attractive to customers (i.e., longer travel time durations, } \\
\text { including distances and connecting flights). By approximating an hourly value of } \\
\text { time, we can monetize the cost perception of a particular ticket in the customer } \\
\text { utility function. }\end{array}$ \\
\hline Advance purchase time & $\begin{array}{l}\text { Tactical airfare pricing strategies by airlines are assumed to be a function of } \\
\text { several factors. One significant factor is how early a customer decides to purchase } \\
\text { a ticket prior to the actual departure date. This state variable for each customer is } \\
\text { considered in the airline agent logic for adjusting airfare offerings for a specific } \\
\text { customer. }\end{array}$ \\
\hline Departure time preference & $\begin{array}{l}\text { We assume that departure time preference is a factor in the customer's ticket- } \\
\text { choice decision; this agent-specific value is used to evaluate ticket choices, } \\
\text { weighting their preferences toward itinerary options that depart closest to the } \\
\text { preferred departure time or earlier. We use this variable to capture the general } \\
\text { behavior of business travelers; when leaving home, they take flights early in the } \\
\text { day, and when returning home, they take flights later in the day. Leisure travelers } \\
\text { are assumed to be insensitive to the travel time. }\end{array}$ \\
\hline Airfare sensitivity & $\begin{array}{l}\text { Airfare sensitivity reflects how significant airfare is to the customer, which is } \\
\text { specific to the traveler type. Higher price sensitivity means that a customer cares a } \\
\text { great deal about price and wants to spend less money. This state variable is an } \\
\text { input into the customer's determination of the most preferable ticket choice. }\end{array}$ \\
\hline Willingness to pay & $\begin{array}{l}\text { WTP is used in the ticket choice submodel of the customer agents to generate a } \\
\text { subset of all offered tickets whose airfares are acceptable to a customer agent. }\end{array}$ \\
\hline Wealth & $\begin{array}{l}\text { This measure is an approximation of customer wealth, which we assume is } \\
\text { separate from income, though highly correlated. Measure of wealth is used in the } \\
\text { airline ticket choice submodel. }\end{array}$ \\
\hline
\end{tabular}

Customer agents possess only one decision-making behavior. They select which available ticket they will purchase, based on a cost- and inconvenience-minimizing utility function, with some degree of randomness. We 
assume that customer agents are not completely rational and, therefore, with some random probability, do not strictly maximize their utility decisions. These behaviors are discussed in more detail in the submodels section.

\section{Airline Agents and State Variables}

The primary entities of AIRLINE-EVOS are airline agents. Airline agents possess behavior rule-sets that influence how they price their airfares and adjust fleet allocation in their flight schedules. They do so through an iterative learning process that involves both tactical and strategic decision logic. Modeling of these behaviors requires (1) generation or input of the airline agents, their starting flight schedules, and an initial allocation of aircraft equipment across the schedule; (2) relevant state variables; and (3) decision logic for dynamic airfare pricing, flight schedule adjustment, and equipage of new technology for airline fleets. The airline agent state variables used in AIRLINE-EVOS are described in Table A2.

Airline agents must also possess computational methods for accurately initializing, accessing, and updating all state variables, in particular, all those related to flight management, such as tracking seat availability for each individual flight as customers purchase tickets and take up available seats. Available capacity changes in a market will have the most direct influence on the competitive response behaviors of the airline agents.

Airline agent decisions are based on profit-maximizing utility functions and, as such, are dependent on ticket purchasing decisions by the customer agents. That modeling enables a determination on how to allocate revenues and market share among the representative airlines being modeled and, subsequently, influences airline behavior responses for adjusting airfare or reallocating the aircraft equipment across the flight schedule. In the current version of AIRLINE-EVOS, these airline behaviors address the two primary responses by airlines to market forces: dynamic airfare pricing and strategic adjustment to the flight schedule. More specifically, airfare adjustment behaviors customize airfares to the specific customer desiring travel, with respect to how close the ticket purchase is from the day of departure, and the number of seats available on the offered flight at the time of purchase. Schedule changes by the airline agents are strategic equipment gauging decisions that attempt to increase revenues by improving captured market share, and modification of departure time, service frequency, and/or network structure to better capture market demand. Airlines consider equipage decisions on a subfleet basis; a decision is made for a given technology set with cost and benefit assumptions specific to airline and subfleet type.

Most other airline responses are executed over extended time frames, involve high capital costs, and require more complicated decision making, such as deciding on new aircraft purchases, leases, or refurbishment of the existing fleet. These actions will be investigated in future versions of AIRLINE-EVOS.

\section{Model Spatial and Temporal Scale}

The spatial scale is used to measure the flying distance, in nautical miles, between origin and destination pairs. The spatial scale is key for calculating metrics such as fuel burn and travel time.

Regarding temporal scales, AIRLINE-EVOS is dimensionless, meaning the duration of the time steps used during a model run is not specified. Time steps are required only during the learning iterations of the model run.

Each iteration is reflective of a process in which airlines will assess their performance and make appropriate strategic changes to their schedule or pricing. In an iterative way, the market is then reengaged after any changes, and the airlines determine success or failure of those changes with respect to profitability. The outcome of this assessment influences subsequent strategy decisions by the airline. Each learning iteration loop is considered the next available time for the airline to publish and implement a flight schedule change; it is not a specified increment of time. It is also assumed that all learning iterations and the resulting model outcomes for experiment scenarios are within context of the same seasonal period of the starting schedule. 
Table A2. Airline agent state variables.

State Variable

Description

Airline

We do not intend to model the behavior of a specific airline; rather, we model proxy airlines that are representative of similar real-world entities with respect to business model, network, operating costs, and aircraft fleet. Using ATS-wide schedule inputs, airline agents are based on real-world airlines. Business models are primarily full-service (FSC), low-cost (LCC), and regional carriers.

Flight schedule Input flight schedules are a standard, real-world ATS-wide schedule, in ACES schedule input file format (FDS-2 or FDS-3). This input schedule includes the following for every flight: origin and destination airports, aircraft type assigned to the route, departure time, filed cruise speed and altitude, and route waypoints.

Feasible set of flight itineraries Airline agents determine a feasible solution set of all possible itineraries for a specific O-D pair, constrained to the airline's network as specified in the input schedule for the given airline's real-world counterpart. Currently, our generated itineraries are either nonstop or have one connection.

Fleet inventory Each airline agent is assigned an aircraft fleet based on the actual fleet inventory for their real-world airline counterpart, using Enhanced Traffic Management System (ETMS) and Aviation System Performance Metrics (ASPM) data, or for future time frames, projected fleet inventories.

Fleet allocation assignment to We assign specific aircraft to the flight schedule according to the allocation the schedule

specified in the input flight schedule

Each airline subfleet is assigned an average age, based on available online
enable consideration of aircraft retirement in the model's equipage logic.

Subfleet categorization $\quad$ AIRLINE-EVOS categorizes each subfleet based on the ease with which new technology/avionics can be installed. In analyses for different equipage scenarios, these categories are associated with specific costs for each category type.

Technological performance of Aircraft performance variables (e.g., customer capacity of the aircraft, cruising the aircraft fleet altitude, speed, acceleration, and fuel burn rate during the climb, cruise, and descent phases of flight) are assigned to each aircraft and then applied to each flight accordingly. The capacity is used to track the number of available seats on the route. The other metrics are used to calculate the aircraft's total fuel burn and total travel time in the air. Variables are derived from Base of Aircraft Data (BADA). ${ }^{8}$

Hedged fuel price Due to their unique business models and corporate strategies, each airline agent has a different price that it pays for fuel.

Airline-specific operating costs Each airline agent is assigned a specific operating cost by flight, accounting for by flight nonfuel-related and fuel-related expenses. Nonfuel-related operating costs are represented by operating costs per flying hour, based on Bureau of Transportation Statistics (BTS) ${ }^{9}$ data, which is specific to the business model of the airline and the aircraft type being flown. Fuel-related operating costs are based on the assigned aircraft type, travel time, fuel burned, and airline hedged fuel price. This is a factor in determining a flight's base airfare and the airline's profit determination.

Airline-specific delay cost $\quad$ Each airline agent is assigned a specific cost of delay for each aircraft type in its fleet, used for calculating monetized benefits from operational savings due to delay reductions.

Airline performance metrics $\quad$ State variables associated with airline performance metrics are dynamic and are continuously updated throughout the AIRLINE-EVOS model run. The airline performance metrics include available seat capacity by flight and load factor by flight.

Airline and flight profits $\quad$ For a given airline, profit is determined by a straightforward calculation of the difference between the summed revenue and the operating costs, across every flight that the airline operates on its schedule. This state variable is used as a trigger mechanism for initiating airline behaviors.

\section{Process Overview and Scheduling}

The dynamics of the model involve the processes that change the state variables of the model entities, describing who does what, in what order, and when the state variables are updated, specific to how time is being modeled. This process overview describes AIRLINE-EVOS, from the instantiation of agent populations, to their interactions, 
behavioral responses, learning iterations, and, ultimately, the generation of an adjusted ATS-wide flight schedule. Fig. A1 shows a high-level modeling flow diagram that illustrates the AIRLINE-EVOS process, scheduling, and interaction points between the agents. The process flow shown in Fig. A1 are described in the following steps:

Step 1. A customer agent population is generated for each O-D pair based on market elasticity assumptions, calibrated to DB1B data, and assigned attributes based on TSAM demographics. TSAM calibration also updates a customer's WTP attribute.

Step 2. An airline agent population is instantiated, based on predetermined representative airline business models. Each airline agent loads an initial flight schedule, aircraft equipment-related data, and fleet allocation assignments. TSAM calibration also updates an airline's base market price.

Step 3. Feasible customer itineraries for each O-D pair are generated from the initial airline schedules. Perceived O-D market value and airline-specific operational costs are considered in the determination of the airline-specific base airfare to be offered for each itinerary.

Step 4. Customer agents request itinerary options from the airline agents based on desired travel for a particular O-D pair, assigned as an attribute at instantiation.

Step 5. Airline agents evaluate the base airfare of the requested itinerary using a cost basis, making pricing adjustments to the airfare based on the advance purchase time of the requesting customer agent and on the remaining seat availability at time of purchase. This is done for each itinerary that the airline agent is offering the customer.

Step 6. Customer agents make a utility maximizing choice, with some randomness, to determine which airline ticket to purchase. Steps 4, 5, and 6 are taken for all customer agents in our model population. Each is handled one at a time in sequential order based on when the customer decided to purchase a ticket, determined from their attribute value for advance purchase time.

Step 7. Each customer purchase feeds back into the airlines' airfare calculations. Choices made by customer agents dynamically influence pricing adjustments the airlines make to better compete in the O-D market. In other words, as each customer agent chooses what ticket to purchase, subsequent customers may have uniquely different choices to consider as the supply of available customer seats diminishes from earlier transactions. Steps 6 and 7 may be thought of as an internal loop that is repeated until all customers have made an airfare decision.

Step 8. Metrics like seat availability are tracked and updated for each flight and for all airlines as tickets are purchased. Profits are also updated on a flight-by-flight basis and aggregated to an airline route and overall airline basis. Likewise, airline market share in an O-D market is updated as tickets are sold.

Step 9. After all customer agents have made their selection, airline agents assess their current operational and financial state. Considering strategic behavior rule-sets, they may adjust their fleet allocation, including the gauging of scheduled aircraft. Alternatively, they may change the base fare price in individual markets to initiate or respond to competitive actions or to adopt a different economic operating point in particular markets to aggressively try to gain more market share. Equipage decisions for new technology are also made at this point in the AIRLINE-EVOS process. These strategies are applied in a sequential orderbased on SME input - and include (1) market base airfare adjustment, (2) network modification, (3) departure time modification, and (4) equipment/gauge swapping.

Step 10. For each type of airline strategy implemented, a feedback loop is executed in which the same customer agent population is reengaged to consider the resulting new set of itinerary and airfare options. This is representative of an airline trying to improve its performance by testing new schedule and airfare strategies at the next available incremental schedule change opportunity. It is a "learning" process, repeated until some convergence or modeling threshold is reached. These strategies are all part of a single iteration of AIRLINE-EVOS. Despite the strategies being executed in an order preferred by real-world airlines, we believe we must run multiple iterations of AIRLINE-EVOS within each iteration of ATS-EVOS. These nested iterations of AIRLINE-EVOS should facilitate a convergence of strategic decision outcomes and further mitigate any undesirable effects due to the specific ordering of strategies.

Step 11. The resulting ATS-wide schedule aggregates the adjusted flight schedules from all the modeled airline agents. This consolidated schedule is now available for input into NASA's ACES, along with cargo carrier schedules, international gateway flights, and projected flight schedules for UASs, to determine ATS-wide impacts as a consequence of airline decisions. 


\section{B. Design Concepts}

The ODD protocol identifies 11 design concepts that are key to robustly describing the dynamics and behaviors of complexity models we expect to observe. The following describes how AIRLINE-EVOS exhibits these design concepts.

\section{Basic Principles}

Central to AIRLINE-EVOS are the dynamic interactions between customer choices, airline decisions, and the performance of the ATS as a whole. As illustrated in Fig. A1, airline agents interact by providing airfares and itineraries to customer agents, and they evolve over multiple learning iterations through strategic pricing and scheduling changes that allow them to better compete in the market and gain revenue.

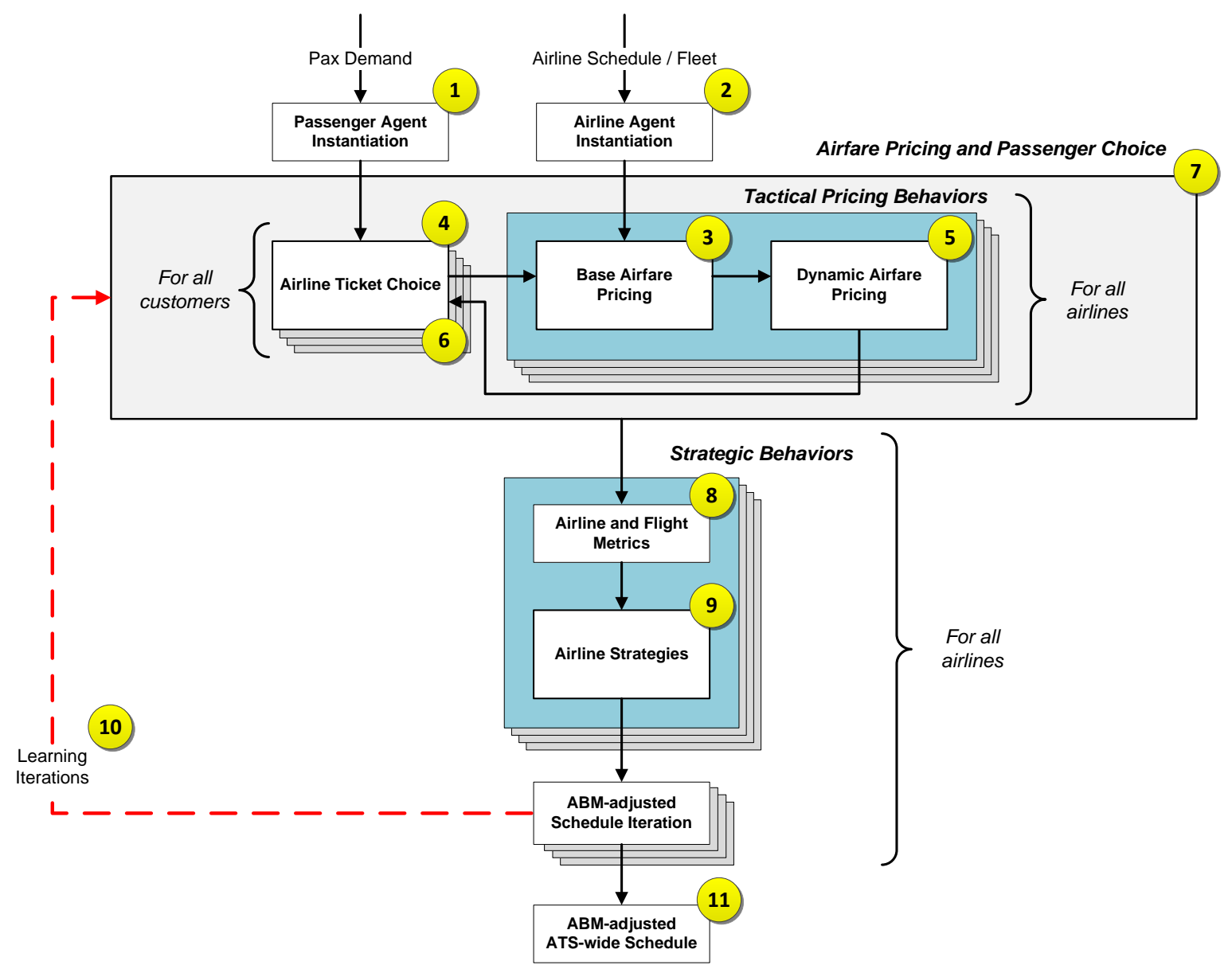

Figure A1. Overview of the AIRLINE-EVOS Process Flow.

\section{Emergence}

Airlines dynamically modify airfares as they are purchased, based on customer advance purchase time characteristics and the available seats for a given flight, and this gives rise to several emergent behaviors in AIRLINE-EVOS:

- Market-based dynamics of customers, with respect to purchasing behaviors over time and travel trends by traveler type and O-D pair (e.g., leisure travel on a decreasing trend in certain markets).

- Competitive airline behaviors, with respect to how airfares change over time, change in profit, and the resulting evolution of market share. 
- Airline operations, with respect to load factor trends and equipment gauging by market, in addition to decisions to equip their fleets with new technology.

- Other emergent effects at the ATS-level are expected to result after running AIRLINE-EVOS schedule output in ACES. These operational-related performance metrics include measures of airspace congestion, delay, violation of safe separation, and others.

\section{Adaptation}

The airlines alter schedules and airfares over time to account for changes in the competitive environment and the resulting suboptimal schedules.

- The airlines potentially sell different numbers of tickets for their flights during each iteration, which can result in financial losses at the flight level that can be corrected through changes to the schedule.

- The airlines change equipment assignments and modify ticket prices based on customer purchasing behavior, which is in turn a reaction to airline schedule offerings. Airlines observe which itineraries are selling well and which are not, and swap aircraft between flights to best match scheduled offerings to demand. Likewise, airlines respond to customer demand by raising or lowering prices. Competing airlines also make price and schedule adjustments, to the effect that when they are responding to customer demand patterns, they are also responding to the competitive actions of other airlines.

\section{Objectives}

Airlines have the explicit objective of maximizing short-term profit. They make changes to their schedule and to ticket prices, then evaluate those changes based on their effect on profit. Customers pursue their objective of maximizing their utility. In every iteration of the model, customers explicitly choose the ticket that will maximize their utility, taking into account their individual preferences.

\section{Learning}

Airline agents change their adaptive traits over time. After all customers have made ticket purchasing decisions during an iteration, airlines reassess the performance and profitability of previous changes to those behaviors and either abandon those changes and take a different approach, or they build on the previous changes to further improve performance and profitability. The airlines learn to make gradual changes to airfares, both to learn the ideal airfare for a particular market and to allow the airfare to drift when significant changes to the market affect the pattern of customer behavior. Likewise, airlines make gradual changes to the schedule to better accommodate current market conditions.

\section{Prediction}

Predictive behavior is not present in the current version of AIRLINE-EVOS although there are plans for airline agents to include the ability to consider the impact of forecasted competitive behavior and market reactions before acting themselves, in addition to the iterative learning already modeled.

\section{Sensing}

Airlines have imperfect awareness of their environments. They know what tickets they have sold in the current iteration in response to the prices they have imposed, and they keep track of the seat availability of their own flights, as well as the amount of time remaining until departure, but they know little else.

\section{Interaction}

Airlines and customers interact directly, with the airlines offering itinerary choices and airfares and the customers choosing a ticket to purchase. Airlines also interact indirectly with each other, mediated through customer ticket transactions that change the remaining unmet customer demand in a market, a shared resource for which airlines compete.

\section{Stochasticity}

Stochastic processes, based on pseudorandom numbers, are used when assigning certain state variables to customer agents (e.g., preferred departure time, traveler type), and when determining whether customers will choose the ticket that maximizes their utility or act irrationally and choose an alternative ticket in a random manner. 


\section{Collectives}

The current AIRLINE-EVOS has no collectives. Airline agents cannot be grouped by common traits, and each market defines a different, unique customer environment.

\section{Observation}

AIRLINE-EVOS currently employs extensive observation into processes in the model, most prominently through the use of logging statements, but also through special purpose output files created to generate a more processed form of quantitative output, ready for analysis and a final schedule file.

\section{Details}

\section{Model Initialization}

The state variables described for airline and customer agents in Tables 1 and 2 are initialized to values derived from assumed distributions, point-value estimates, BTS data sources ${ }^{9}$, and other freely available information from the Internet. Please reference the full NASA report complete details of our model initialization assumptions. ${ }^{6}$

\section{Submodels}

Currently, AIRLINE-EVOS implements eight submodels that enable agents to assess and interact with their environments. Table A3 describes the role and function of each submodel.

\section{Table A3. AIRLINE-EVOS Submodels.}

\begin{tabular}{|c|c|c|}
\hline Agent Type & Submodel & Description \\
\hline Customer & Airline Ticket Choice & $\begin{array}{l}\text { Customers decide upon a ticket to purchase from flights matching their } \\
\text { desired origin and destination. The Airline Ticket Choice submodel } \\
\text { models the customer decision-making process by mathematically } \\
\text { modeling the utility of the individual tickets to the customer evaluating } \\
\text { them. }\end{array}$ \\
\hline \multirow[t]{7}{*}{ Airline } & Flight Cost & $\begin{array}{l}\text { Airlines determine the operating costs of their flights, based on a number } \\
\text { of factors that include the technological performance specific to the } \\
\text { aircraft equipment being used on the flight. }\end{array}$ \\
\hline & Profit Calculation & $\begin{array}{l}\text { Airlines calculate profit at the flight and airline levels, the results of } \\
\text { which trigger behavioral responses by the airlines. }\end{array}$ \\
\hline & Dynamic Airfare Pricing & $\begin{array}{l}\text { Airlines adjust offered airfares depending on the time remaining until the } \\
\text { date of travel and on the number of tickets remaining to be sold for } \\
\text { individual flights. }\end{array}$ \\
\hline & Network Modification & $\begin{array}{l}\text { Airlines explore the modification of either the origin or destination of } \\
\text { poorly profiting flights, in an effort to gain greater profit. }\end{array}$ \\
\hline & $\begin{array}{l}\text { Departure Time } \\
\text { Modification }\end{array}$ & $\begin{array}{l}\text { Airlines explore the modification of flight departure times of poorly } \\
\text { profiting flights, in an effort to gain greater profit. }\end{array}$ \\
\hline & $\begin{array}{l}\text { Airline } \\
\text { Equipment Swapping }\end{array}$ & $\begin{array}{l}\text { Once tickets have been sold, airlines may choose to switch equipment } \\
\text { for flights to better accommodate market demand or to better match the } \\
\text { equipage or performance profile to market and demand characteristics. }\end{array}$ \\
\hline & $\begin{array}{l}\text { Technology } \\
\text { Equipage Decision }\end{array}$ & $\begin{array}{l}\text { Airlines weigh, on a subfleet basis, costs and benefits for given } \\
\text { technology sets and decide if they will equip their subfleets. }\end{array}$ \\
\hline
\end{tabular}

\section{Acknowledgments}

This work was accomplished under NASA research announcement (NRA) NNH10ZEA001N, "Research Opportunities In Aeronautics-2010", Amendment 6, NextGen - Systems Analysis Integration And Evaluation Projected C.3 Subtopic 2: Comprehensive Modeling Of Air Carrier Behavior. The authors would also like to thank 
William Cotton of Cotton Aviation Enterprises and Vince Costanzo for their counsel and advice, and Jeffrey

Goldsmith, James Hebden, and Terry Thompson of LMI, for their contributions and support of this research.

\section{References}

${ }^{1}$ Horio, B. M., A. H. DeCicco, V. L. Stouffer, S. Hasan, R. L. Rosenbaum, and J. C. Smith. 2014. "Agent Based Modeling of Air Carrier Behavior for Evaluation of Technology Equipage and Adoption." In Proceedings of the 14TH AIAA Aviation Technology, Integration, and Operations Conference. Reston, Virginia: American Institute of Aeronautics and Astronautics.

${ }^{2}$ Lempert, R. "Agent-Based Modeling as Organizational and Public Policy Simulators." Proceedings of the National Academy of Sciences of the United States of America. Vol. 99.Suppl 3, 2002. pp. 7195-7196.

${ }^{3}$ Baik, H., and Trani, A. A. "A Transportation Systems Analysis Model (TSAM) to Study the Impact of the Small Aircraft Transportation System (SATS)” (presentation, 23rd International Conference of the System Dynamics Society, 2005).

${ }^{4}$ Horio, B. M., Kumar, V., and A. H. DeCicco. "An Agent-Based Approach to Modeling Airlines, Passengers, and Policy in the U.S. Air Transportation System", 2015 Winter Simulation Conference, INFORMS (submitted for publication).

${ }^{5}$ Sweet, D., Manikonda, V., Aronson, J., Roth, K., and Blake, M., "Fast-Time Simulation System for Analysis of Advanced Air Transportation Concepts," AIAA-2002-4593, American Institute of Aeronautics and Astronautics, AIAA Modeling and Simulation Technologies Conference and Exhibit, Monterey, CA, Aug. 2002.

${ }^{6}$ Kumar, V., Horio, B. M., A. H. DeCicco, S. Hasan, V. L. Stouffer, J. C. Smith, and N. Guerreiro. 2015. "Understanding Air Transportation Market Dynamics using a Search Algorithm for Calibrating Travel Demand and Price." In Proceedings of the 15TH AIAA Aviation Technology, Integration, and Operations Conference. Reston, Virginia: American Institute of Aeronautics and Astronautics.

${ }^{7}$ Grimm, V., Berger, U., Bastiansen, F., Eliassen, S., Ginotet, V., Giske, J., and et al., "A Standard Protocol for Describing Individual-based and Agent-based Models," Ecological Modelling, Vol. 198, Issues 1-2, Sept. 2006, pp. 115-126.

${ }^{8}$ Grimm,V., Berger, U., DeAngelis, D. L., Polhill, J. G., Giske, J., and Railsback, S. F., "The ODD Protocol: A Review and First Update," Ecological Modelling, Vol. 221, Issue 23, Aug. 2010, pp. 2760-2768.

${ }^{9}$ Johnson, T., "Departure Delays, the Pricing of Congestion, and Expansion Proposals at Chicago O'Hare Airport," Journal of Air Transport Management, Vol. 12, No. 4, July 2006, pp. 182-190.

${ }^{10}$ Horio, B. M., V. Kumar, A. H. DeCicco, J. H. Goldsmith, S. Hasan, J. S. Hebden, V. L. Stouffer, T.R. Thompson, Comprehensive Modeling of Air Carrier Behavior: Final Report, NS403T3, McLean, VA: LMI, March 2015.

${ }^{11}$ InterVISTAS Consulting, Inc., Estimating Air Travel Demand Elasticities: Final Report, prepared for the International Air Transport Association, December 2007.

${ }^{12}$ Mavris, D. N., and Garcia, E., Decision Making Support for NASA's Aeronautics Research Mission Directorate, NAS102117, Contract 6075, March 2007. 